\title{
Relationship Between Iranian L2 Learners' Intercultural Communicative Competence and Personality Traits
}

\author{
Mahmood Hashemian ${ }^{1,}$, Maryam Farhang-Ju² \\ ${ }^{1,2}$ Shahrekord University, Chaharmahal and Bakhtiari Province, Iran \\ *Corresponding author: hashemian-m@sku.ac.ir
}

\begin{abstract}
The rapid development of communication technologies has facilitated communication between citizens with diverse personality traits. As intercultural communicative competence (ICC) has recently found its way into L2 theory and research, not only is it important for L2 learners to gain knowledge of ICC but also it is essential to be aware of personality traits. Therefore, through investigating the (possible) relationship between ICC and personality traits, this study was an attempt to gain knowledge of L2 learners' ICC and personality traits/types profiles. For this purpose, 165 upper-intermediate L2 learners (70 males and 95 females) participated in this study. Then, they filled out the ICC questionnaire and the MyersBriggs Type Indicator (MBTI) in different sessions. Data were analyzed through Pearson product-moment correlation coefficients, independent samples $t$-test, and one-way ANOVA. Results indicated that (1) the participants were stronger at the introvert trait and extravert, intuitive, feeling, and judging type, (2) there was no relationship between the eight personality traits and the ICC scores, (3) the participants' gender differences had no significant effect on their ICC scores, (4) and there were no statistically significant differences between the participants' ICC scores for the three age groups. Findings are theoretically and practically significant. Pedagogical implications and suggestions are discussed in detail.
\end{abstract}

Keywords: Intercultural communicative competence (ICC), Personality traits, Gender differences

\section{Introduction}

Nowadays, the world has growingly become interrelated and is regarded as a village in which people need to communicate effectively with different cultural ethnicities. As second/foreign language (L2) communication requires not only linguistic knowledge, but also knowledge of cultural rules that govern that language and discourse. As a result, intercultural communicative competence (ICC) plays an 
important role in international communication (Deardorff, 2006). The notion of ICC is based on the idea that $\mathrm{L} 2$ learners need to develop the necessary knowledge related to attitudes and values, skills of interpreting and relating, skills of discovery and interaction, as well as critical cultural awareness (Byram, 2009).

The cultural adaptation is considered as the ICC's most essential basic. In recent years, scholars (e.g., Rezaei, \& Naghibian, 2018; Ruan \& Medwell, 2019) have argued that a successful L2 instruction simplifies the interaction of L2 learners with other people who are linguistically and culturally different from them. Subsequently, ICC can be brought into L2 learning in order to improve it.

Researchers (e.g., Guranda, 2012; Hashemian \& Fadaei, 2012; Hashemian \& Farhang-Ju, 2018; Hashemian, Jafarpour \& Adibpour, 2015; Hashemian, Mirzaei, \& Mostaghasi, 2016; Tao \& Li, 2014) have emphasized individual differences as the fundamental building blocks of the process of L2 learning for L2 teachers by which they can analyze, motivate, and assist their students. As McDonouch and Shaw (2003) suggest, in terms of adjusting and deviating certain aspects of the classroom, understanding L2 learners' characteristics has implications for L2 classrooms. One of the individual differences is personality traits.

With regard to personality traits, further research should be done to see if people with personality traits benefit from different levels of ICC. Given the essential position of the two factors of ICC and personality traits in L2 learning and pedagogy, the present research perceived it as particularly illuminating to make an effort to relate these two dominant variables.

In fact, this study aimed to see whether personality traits can predict the success of L2 learners in intercultural (business) contacts. In spite of the relative universal importance of ICC, little is known about the (possible) relationship between L2 learners' ICC and personality traits. Considering the importance of the two factors in L2 learning, the present study was an attempt to find the (possible) relationship between these two influential variables and to detect the (possible) effect of gender and age on L2 learners' ICC.

\section{Literature Review}

Intercultural Communicative Competence (ICC)

The notion of ICC is defined as "the ability to communicate effectively and appropriately in intercultural situations based on one's intercultural knowledge, skills, and attitudes" (Deardorff, 2006, p. 13). According to this definition, 
knowledge includes cultural self-awareness, broadening culture-related information, and promoting linguistic knowledge. Skills pertain to the ability to communicate across cultures and attitudes involve being sincere to other diverse cultures, thinking positively about other cultures, and coping with ethnocentric behaviors (Deardorff, 2006).

Language and culture are interrelated and the development of one results in promoting the other (Mitchell \& Myles, 2004). Accordingly, it is argued that L2 learning without learning its culture enhances the risk of becoming a fluent fool (Bennett, Bennett, \& Allen, 2003). Recently, L2 researchers have shown a growing interest in the use of socio-cultural theories in education (e.g., Kiet Ho, 2009; Mirzaei \& Forouzandeh, 2013; Oz, 2015).

In order to analyze the underlying assumptions about culture, Kiet Ho (2009) examined two traditional English textbook units used in a Vietnamese university. Using a set of standards for intercultural language learning, he suggested the cultural components of units in order to raise the learners' cultural awareness and engage them cognitively, behaviorally, and affectively in culture learning.

Mirzaei and Forouzandeh (2013) conducted a study to develop a measure of ICC. Also, they investigated the relationship between Iranian L2 learners' ICC and their L2 learning motivation, on the one hand, and between gender and the development of ICC, on the other. They concluded that language socialization or "learners' intercultural dispositions to L2 learning and aligning with otherness influence their L2 motivation, and motivational factors, in turn, guide the learning process and ensure achievement" (p. 312).

Oz (2015) analyzed the relationship between L2 learners' ideal L2 self and ICC and concluded that there was a significant positive relationship between the two concepts. Consequently, the findings revealed that culture was merged with pedagogy and the L2 learners had to improve their ICC in order to be successful in L2 learning.

\section{Personality Traits}

Personality traits are factors that can account for differential success among L2 learners (Brown, 2000). The main tenet of the MBTI is that people prefer certain ways to interpret their experiences, and these preferences are the leading cause of their interests, needs, values, and motivation (Kaplan \& Saccuzzo, 2009). Being the most widely used inventory, MBTI assesses an individual's personality according to four categories: (1) extroversion vs. introversion, (2) sensing vs. intuition, (3) thinking vs. feeling, and (4) judging vs. perceiving (Brown, 2000). These 
dichotomies help L2 researchers and learners understand the individual differences of L2 learners (Kaplan \& Saccuzzo, 2009).

A number of studies have investigated the personality traits of L2 learners. In a study, Wakamoto (2000) realized that the extroverts used more functional strategies and social-affective strategies in L2 learning than the introverts. The extroverts paid more attention to meaning rather than form and asked more questions than the introverts. Finally, he realized that the extroverts would ask for clarification more enthusiastically than the introverts. Therefore, such enthusiasm might help them improve their chances of having the essential input for constructing an interlanguage. The aforementioned literature review shows that there is a necessity to conduct more research in order to shed more light on the issue at hand.

Furthermore, Wakamoto (2007) conducted a study to find correlations between extroversion and L2 learning strategies and English listening proficiency. The findings showed that the extrovert group preferred socio-affective learning strategies, whereas, in the teacher-fronted classroom practice, the participants did not use socio-affective strategies. Moreover, extroversion did not have any effect on the learners' listening proficiency. Hence, the field of research can highlight personality traits as an important concept for successful L2 learning.

Another aspect that plays an essential role in social relations, culture, and individual life is gender (e.g., Hashemian \& Farhang-Ju, 2017; Pan, 2007). Thus, it is crucial to pay more attention to gender in L2 studies, as it was dealt with in the present one.

Considering the role of gender in the ICC level of L2 learners, various studies have been conducted, which yielded contradictory results. For example, it was found that the female L2 learners' ICC levels were higher than the men (Sung \& Padilla, 1998). In contrast, it was reported that the ICC levels for the male L2 learners were higher (Pan, 2007). Nevertheless, other studies revealed no significant relationship between the L2 learners' ICC level and their gender (Matveev, 2002; Patricia, 2005). Accordingly, there is an urgent need further to explore the ICC in connection with gender differences.

Moreover, the fact that ICC and personality traits have relatively universal importance (Guranda, 2012; Wakamoto, 2000, 2007), little is known about the relationship between L2 learners' ICC level and the MBTI personality traits. Given the importance of the two factors in L2 learning and teaching, the present research investigated this issue. The study addressed the following research questions:

1. What are Iranian L2 learners' ICC and personality profiles? 
2. What is the most frequent MBTI personality type among Iranian L2 learners?

3. Is there any significant relationship between Iranian L2 learners' ICC and MBTI personality traits?

4. Is there any significant difference between male and female Iranian L2 learners' ICC?

5. Is there any significant difference in the mean scores of ICC for the three age groups of Iranian L2 learners (i.e., 20 and younger; between 21 and 25; 26 or above)?

\section{Method}

\section{Participants}

The participants were 165 upper-intermediate L2 learners (i.e., 70 males and 95 females) with three age groups (i.e., 20 and younger; between 21 and 25; 26 or above) in an English language institute in Iran. High-intermediate L2 learners were selected to ensure their acceptable command of English so as to respond well to the items in the instrument of the study. With different socioeconomic backgrounds, the participants' educational levels varied from high school diplomas to bachelor's degrees in different majors. They were studying English for almost four years. Besides, they were all exposed to English from the age of 12 to 18 in their secondary school until the last year of high school.

\section{Instruments}

A demographic form was used to elicit characteristics like gender and age. Moreover, to spot the participants' personality traits, form G of the MBTI, as a 94item pencil-and-paper inventory, was administered to the participants. The MBTI has been the focus of widespread investigations, and considerable evidence has been collected, proposing the inventory has acceptable concurrent and predictive validity and reliability (Furnham \& Stringfield, 1993).

Moreover, Myers and McCaulley (1985) assert that all forms of the MBTI have been extensively examined for validity and reliability, and it is found they are all quite proper measurements for the most adult population. Form G of the MBTI, as a standard form, was used in the current study (Myers \& McCaulley, 1985). The Cronbach's alpha reliability coefficient was used, and the reliability of the 
instrument was .75 , which suggested this instrument could be applied as a reliable tool in the present study.

As mentioned earlier, the main purpose of MBTI is to discover four basic preferences. An individual's MBTI score depicts his or her type. In general, MBTI pursues a definite scoring system. The participants had to select any of the two or three choices, indeed.

In the current study, based on the scoring key, the participants' responses for each dichotomous scale were scored in the form of 0 and 1 . For instance, in the extroversion/introversion scale, code 1 was used for each correct answer standing for extroversion, and, conversely, code 0 was used for each correct answer standing for introversion (Moghadasi, 2010). Moreover, as the scale of the maximum score and the number of the questions were equal, the obtained score of each participant in preference was subtracted from the total score to determine his or her score in the opposite preference (Moghadasi, 2010).

To facilitate the calculation of the continuous scores, the score of the lower preference was subtracted from, the higher one, and the difference in outcome was multiplied by 2 and one score was added to them. Lastly, if the higher preference were introversion, intuition, feeling, or perceiving, the results would be added by 100; and if it were extroversion, sensing, thinking, and judging, the results would be minus 100 (Higgs, 2001).

Besides, the ICC questionnaire, adapted from Mirzaei and Forouzandeh (2013), was used to determine the participants' ICC. The ICC questionnaire consisted of 22 statements and was based on Deardorff's (2006) large-scale study. The questionnaire included 12 items for evaluating the participants' knowledge, five items for evaluating the participants' skills in communication with different cultures, and five items for evaluating the participants' respect for and openness to different cultures in addition to their tolerance of ambiguity (Mirzaei \& Forouzandeh, 2013). The participants appraised the statements on a 5-point Likert scale (ranging from strongly disagree to agree strongly). The higher scores on the test showed higher ICC levels $(\operatorname{Min}=22 ; \operatorname{Max}=110)$. The reliability of the ICC questionnaire was .71 , using Cronbach's alpha.

\section{Procedure}

Before conducting the study, the current researchers introduced themselves to the participants and explained the purpose of the study. To ensure the anonymity of the data, a code system was designed, and each participant was given a code, rather than writing their names down on the questionnaires. The participants were assured that 
the data would be used for the research purpose and the results would not affect their grades.

The participants filled out the instruments in different sessions to avoid factors that may affect the reliability of the results like fatigue. An adjunct questionnaire was exploited so as to gather the participants' required demographic information (e.g., gender and age).

Then, the ICC questionnaire adapted from Mirzaei and Forouzandeh's (2013) study and the MBTI were administered to the participants in different sessions. Finally, SPSS was used to analyze the data.

\section{Results}

To demonstrate an overall description of the data, descriptive statistics (i.e., minimum and maximum scores, mean, and standard deviation) were calculated for the eight personality traits and ICC as well as one for the frequencies of the personality types.

Table 1 shows the results of the descriptive statistics for the participants' scores on the two questionnaires to answer the first research question:

Table 1

Descriptive Statistics of the Eight Personality Traits and ICC

\begin{tabular}{|l|c|c|c|c|c|}
\hline Variables & $N$ & Min & Max & $M$ & $S D$ \\
\hline ICC & 165 & 65 & 98 & 81.06 & 9.424 \\
\hline Extroversion & 100 & 65 & 97 & 87.80 & 9.09 \\
\hline Introversion & 65 & 103 & 135 & 113.46 & 10.14 \\
\hline Sensing & 80 & 67 & 95 & 89.00 & 7.87 \\
\hline Intuition & 85 & 101 & 133 & 112.29 & 9.19 \\
\hline Thinking & 70 & 81 & 97 & 90.43 & 6.20 \\
\hline Feeling & 95 & 103 & 127 & 110.58 & 7.04 \\
\hline Judging & 125 & 55 & 95 & 77.24 & 10.96 \\
\hline Perceiving & 40 & 101 & 125 & 111.00 & 8.28 \\
\hline
\end{tabular}

As shown in Table 1, the participants' ICC scores ranged from 65 to 98, with a mean score of 81.06. Moreover, Table 1 depicts that the leading personality trait among the Iranian upper-intermediate L2 learners was the introvert trait $(M=113.46)$, and the least common trait was the judging trait $(M=77.24)$. 


\section{Table 2}

Descriptive Statistics of the Sixteen Personality Types

\begin{tabular}{|l|c|c|}
\hline Variables & Frequency & Percentage \\
\hline ISTJ & 20 & 12.1 \\
\hline ISFT & 10 & 6.1 \\
\hline INTJ & 5 & 3.0 \\
\hline ISTP & 10 & 6.1 \\
\hline ISFP & 15 & 9.1 \\
\hline INFP & 5 & 3.0 \\
\hline ESTP & 5 & 3.0 \\
\hline ENFP & 5 & 3.0 \\
\hline ESTJ & 10 & 6.1 \\
\hline ESFJ & 10 & 6.1 \\
\hline ENFJ & 50 & 30.3 \\
\hline ENTJ & 20 & 12.1 \\
\hline Total & 165 & 100.0 \\
\hline
\end{tabular}

According to Table 2, the most common personality type among the Iranian upperintermediate L2 learners was the ENFJ type (30.3) and the least common types were the INTJ, INFP, ESTP, and ENFP types, with the frequency of 3.

With the purpose of investigating the relationship between the Iranian upperintermediate L2 learners' ICC and their MBTI personality traits, a Pearson productmoment correlation was run (see Table 3):

\section{Table 3}

Results of Pearson Product-Moment Correlation for Iranian Upper-Intermediate L2 Learners' ICC and MBTI Personality Traits

\begin{tabular}{lcccccccc}
\hline $\begin{array}{l}\text { Varia } \\
\text { ble }\end{array}$ & $\begin{array}{c}\text { Extrover } \\
\text { sion }\end{array}$ & $\begin{array}{c}\text { Introver } \\
\text { sion }\end{array}$ & $\begin{array}{c}\text { Sensi } \\
\text { ng }\end{array}$ & $\begin{array}{c}\text { intuiti } \\
\text { on }\end{array}$ & $\begin{array}{c}\text { Thinki } \\
\text { ng }\end{array}$ & $\begin{array}{c}\text { Feeli } \\
\text { ng }\end{array}$ & $\begin{array}{c}\text { Judgi } \\
\text { ng }\end{array}$ & $\begin{array}{c}\text { Perceiv } \\
\text { ing }\end{array}$ \\
\hline ICC & -.056 & .16 & -.07 & .07 & -.30 & -.00 & -.03 & .40 \\
& .82 & .59 & .79 & .80 & .30 & .99 & .88 & .32 \\
\hline
\end{tabular}

As Table 3 shows, there were no correlation coefficients between the eight preferences of personalities and the ICC scores.

An independent-samples $t$-test was conducted to find out whether there was any significant difference between the ICC scores of the male and female L2 learners. The $t$-test results for the two groups' ICC scores are presented in Table 4: 


\section{Table 4}

Independent Samples $t$-Test for the Male/Female ICC Differences

\begin{tabular}{|l|c|c|c|c|c|c|}
\hline & Gender & $N$ & $M$ & $S D$ & $t$ & Sig. \\
\hline \multirow{2}{*}{ ICC } & Males & 70 & 82.9 & 10.3 & .98 & .43 \\
\cline { 2 - 7 } & Females & 95 & 79.7 & 8.7 & & \\
\hline
\end{tabular}

As Table 4 vividly shows, there was no significant difference between the male L2 learners' ICC mean score $(M=82.9, S D=10.3)$ and that of the females $(M=79.7$, $S D=8.7), t(165)=.98, p=.43$. That is, the Iranian L2 male learners did not perform differently on the ICC questionnaire in comparison with the female learners. The magnitude of the differences in the means was minimal $\left(\eta^{2}=.03\right)$, suggesting that gender differences did not seem to have caused significant differences in the participants' ICC level in this study.

The last research question of the study was intended to unfold whether there was a significant difference in the mean scores of the ICC for the three age groups of the Iranian L2 learners (i.e., 20 and younger; between 21 and 25; 26 or above). To achieve this aim, one-way between-groups ANOVA was conducted for the comparison of the ICC scores of the three age groups. There were no statistically significant differences between the group means as determined by the one-way ANOVA, $F[2,162]=.56, p=.58$ (see Table 5):

Table 5

Results of One-Way ANOVA for Comparing ICC Scores of the Three Groups

\begin{tabular}{|l|c|c|c|c|c|}
\hline & $\begin{array}{c}\text { Sum of } \\
\text { Squares }\end{array}$ & $d f$ & $M S$ & $F$ & Sig. \\
\hline Between Groups & 101.88 & 2 & 50.94 & .56 & .58 \\
\hline Within Groups & 2739.10 & 160 & 91.33 & & \\
\hline Total & 2841.88 & 162 & & & \\
\hline
\end{tabular}

\section{Discussion}

The current study aimed to investigate the upper-intermediate L2 learners' perceptions of the ICC and personality traits and types. The results of descriptive statistics for the participants' eight traits of personality indicated that the most common trait was introvert and the least common trait was judging. 
The introverts enjoy a better ability to consolidate learning. Thus, compared to the extroverts, their less distractibility and better study habits may facilitate acquiring better consequences in learning (Dörnyei, 2005). Hence, in the current study, the high mean score of the introvert trait in the sample may suggest that the participants inclined to be more introverted. Simply put, they were probably more meticulous about their strengths and weaknesses because, in the context of Iran, some traditional methods like the grammar-based method in which, generally, the focus was on the L2 learners' errors and pushing them into being introverted.

Besides, the most frequent personality type among the participants was the ENFJ type. This finding is in line with Nosratinia, Shakoori, and Zaker's (2013) study. An ENFJ individual is extrovert, preferring judging, with extensive mental functions, intuition, and feeling. This may be claimed that such learners want to feel everything is settled, and their idealism destines them for attempting hard while achieving their objectives.

Furthermore, the findings of the present study indicated no significant relationship between the participants' ICC and their MBTI personality traits. The results are in disagreement with Yashima (1995). His findings indicated that personality played an important role in intercultural adjustment and suggested to inaugurate intercultural skill training that can improve L2 learners' interactional effectiveness.

The reason for such results may be due to another factor, like L2 learners' proficiency. Many studies have investigated the effect of individuals' personality traits on L2 (here, English) proficiency (Wakamoto, 2007). Therefore, applying the best learning strategies which are based on different personality traits is so fruitful to push forward the L2 learners' learning process. Additionally, an appropriate acquaintance with the personality traits sounds to be important in social communications (Guranda, 2012).

Of the other findings of the current study was that there was no relationship between the ICC and the participants' age. The results of the present study confirm Mirzaei and Forouzandeh's (2013) investigation in which it was revealed that the L2 learners' gender had no significant relationship with ICC. However, more inquiry is required to apply the more precise methodology and a larger sample because, in the literature, contradictory results can be observed. In some investigations, it was revealed that the females' intercultural competence was higher than that of the males (e.g., Sung \& Padilla, 1998).

On the basis of the data analyzed through the one-way between-groups ANOVA, the findings revealed that there were no statistically significant differences in the mean scores of ICC for the three age groups of the Iranian L2 learners (i.e., 20 and younger; 
between 21 and 25; 26 or above). Thus, the findings contradict previous findings by Ajitoni (2014), in which it was asserted that age had a significant main effect on the intercultural competence of the students and achievement in social studies. Clearly, more studies should be done as conflicting results exist in the literature.

\section{Conclusion}

This study aimed to discover Iranian upper-intermediate L2 learners' ICC and personality profiles. The introvert trait was considered as the most common personality trait among the participants, and the judging trait was the least common trait. Furthermore, the ENFJ type was reported as the most frequent personality type among the participants, and the least common traits were INTJ, INFP, ESTP, and ENFP types. Second, there was no correlation between the eight preferences of personalities and the ICC scores among the participants. Third, it was determined that the participants' gender differences had no significant effect on their ICC scores. Fourth, the results pointed to the fact that there were no statistically significant differences in the mean scores of ICC for the three age groups of the participants (i.e., 20 and younger; between 21 and $25 ; 26$ or above).

Some theoretical and pedagogical implications can be extracted from the findings of this study. The findings showed that there was no significant relationship between the participants' personality traits and their ICC scores. However, the findings indicated that knowing L2 learners' personality profiles, in some cases, can be of great help to L2 learning/teaching. Simply put, the results suggest that L2 learners with different personality traits who want to communicate to other cultures are at similar levels of ICC. In more practical terms, L2 learners with different personality traits might have higher or lower levels of ICC.

As the results of previous research along with this paper contradict each other, generalizations should be kept away from this domain. Hence, more research should be done to reach definitive conclusions on this issue. Besides, assessing learners' reflections during the course can be applied in order to expand the various aspects of L2 teaching/learning.

As L2 learners' personality traits are considered among important variables for L2 learning, an L2 teacher is responsible for encouraging L2 learners to be cautious about their personality profiles and the ICC level. Moreover, adopting innovative, encouraging teaching materials to L2 learners with different personality traits may also help L2 teachers in the process of teaching the cultural issues of an L2. Therefore, it is recommended to motivate L2 learners to be successful in L2 
communication in the multicultural, interconnected world by enhancing their intercultural communicative dispositions.

Last but not least, the findings may have some benefits for L2 materials developers. They can develop materials that emphasize the motivating techniques and tools for L2 learning, in general, and activities that help L2 learners to benefit from their personality traits while learning an $\mathrm{L} 2$, in particular.

The present study was an attempt to present new information and findings in the world of individual differences, especially personality traits/types and ICC for L2 learners, but some limitations and delimitations were observed.

A significant limitation in the present study was the size of the sample, as the number of participants was limited. Thus, further studies can employ more participants to find more significant results. As the socio-cultural milieu of Iran enjoys specific cultural issues, Iranian L2 learners' intercultural differences may involve in their communications. Other upcoming studies can detect how these cultural issues can influence the relationship between L2 learners' ICC and their personality traits.

As another limitation, the generalization of the findings can be considered as another problematic area. Because, throughout the study, all the variables were not controlled (e.g., L2 learners' fields of study, physical/mental status). It might have influenced the results.

The most important issue is that the validity of the data relied more on the participants' honesty because both of the questionnaires were self-reports. Taking into account the limitations of this study, further research can use other methods off data collection to scrutinize whether similar results can be found and provide a more comprehensive picture.

In conclusion, we hope the findings help L2 teachers and researchers provide better techniques and methods to move towards individualizing learning and developing L2 learners' ICC through making use of the mentioned contributing factors.

\section{References}

Ajitoni, S. O. (2014). Enhancing Nigerian students' intercultural competence and achievement in social studies through outdoor activities. Journal of Language and Cultural Education. 2 (2), 204-217.

Bennett, J., Bennett, M. \& Allen, W. (2003). Developing intercultural competence in the language classroom. In: Lange, D. \& Paige, R. (eds.) Culture as the core: Perspectives 
on culture in second language learning. Greenwich, CT, Information Age Publishing, pp. 237-270.

Brown, H. D. (2000). Principles of language learning and teaching. San Francisco: Addison Wesley Longman.

Byram, M. (2009). Intercultural competence in foreign languages: The intercultural speaker and the pedagogy of foreign language education. In: Deardorff, D. K. (ed.) The SAGE handbook of intercultural competence Thousand Oaks, CA, Sage, pp. 321-332.

Deardorff, D. K. (2006). Policy paper on intercultural competence. Gütersloh, GM, Bertelsmann Stiftung.

Dörnyei, Z. (2005). The psychology of the language learner: Individual differences in second language acquisition. Mahwah, NJ, Lawrence Erlbaum Associates.

Furnham, A. \& Stringfield, P. (1993). Personality and work performance. Personality and Individual Differences. 14, 145-153.

Guranda, M. (2012). Study on the association between personality traits and cultural dimensions. Brasov. 14 (16), 211-214.

Hashemian. M. \& Fadaei, B. (2012). L2 learners' strategy preference in metaphorical test performance: Effects of working memory and cognitive style. Issues in Language Teaching. 1 (2), 279-231.

Hashemian, M. \& Farhang-Ju, M. (2017). Differences in EFL learners' requests to faculty in synchronous computer-mediated communication: The case of gender and proficiency. Research in English Language Pedagogy. 5 (2), 181-202.

Hashemian, M. \& Farhang-Ju, M. (2018). Effects of metalinguistic feedback on grammatical accuracy of Iranian field (in)dependent L2 learners' writing ability. Research in Applied Linguistics. 9 (2), 141-161.

Hashemian, M., Jafarpour, A. \& Adibpour, M. (2015). Exploring relationships between field (in)dependence, multiple intelligences, and L2 reading performance among Iranian L2 learners. Research in Applied Linguistics. 6 (1), 40-63.

Hashemian, M., Mirzaei, A. \& Mostaghasi, H. (2016). Exploring different oral corrective feedback preferences: Role of intrapersonal and interpersonal intelligences. Research in Applied Linguistics. 7 (2), 140-159.

Higgs, M. (2001). Is there a relationship between the Myers-Briggs type indicator and emotional intelligence? Journal of Managerial Psychology. 16 (7), 509-533.

Kaplan, R. M. \& Saccuzzo, D. P. (2009). Psychological testing: Principles, applications, and issues ( $7^{\text {th }}$ ed.). Belmont, CA, Wadsworth.

Kiet Ho, S. T. (2009). Addressing culture in EFL classrooms: The challenge of shifting from a traditional to an intercultural stance. Electronic Journal of Foreign Language Teaching. 6, 63-76.

Matveev, A. V. (2002). The perception of intercultural communication competence by American and Russian managers with experience on multicultural teams. Unpublished doctoral dissertation, Ohio University, Athens.

McDonouch, J. \& Shaw, C. (2003). Materials and methods in ELT. UK, Blackwell Publishing.

Mirzaei, A., \& Forouzandeh, F. (2013). Relationship between intercultural communicative competence and L2 learning motivation of Iranian EFL learners. Journal of Intercultural Communication Research. 42, 300-318.

Mitchell, R. \& Myles, F. (2004). Second language learning theories. London, Arnold.

Moghadasi, R. (2010). Exploring the standardization and reliability of the Myers-Briggs type indicator among the students of Isfahan University. Unpublished master's thesis, University of Isfahan, Iran. 
Myers, I. B. \& McCaulley, M. (1985). Manual: A guide to the development and use of the Myers-Briggs Type Indicator. Palo Alto, CA, Consulting Psychologists.

Nosratinia, M., Shakoori D. N. \& Zaker, A. (2013). Language learners' internal factors and practical applications: A case of vocabulary learning strategies. IOSR Journal of Humanities and Social Science. 17 (1), 100-115.

$\mathrm{Oz}, \mathrm{H}$. (2015). Ideal L2 self as a predictor of intercultural communicative competence. Anthropologist. 19 (1), 41-53.

Pan, S. (2007). Intercultural communication apprehension, ethnocentrism and their relationship with gender: A cross-cultural comparison between the U.S. and China. Paper presented at the annual meeting of the National Communication Association Conference, New Orleans, LA.

Patricia, M. Y. (2005). Asian American adolescents and the stress of acculturation: Differences in gender and generational levels. Unpublished doctoral dissertation, Northern Arizona University, Flagstaff, AZ.

Rezaei, S. \& Naghibian, M. (2018). Developing intercultural communicative competence through short stories: A qualitative inquiry. Iranian Journal of Language Teaching Research, 6 (2), 7796.

Ruan, J. \& Medwell, J. (2019). Using social networking technology to develop intercultural communicative competence: a case of GCSE Mandarin. Innovation in Language Learning and Teaching, 1-31.

Sung, H. \& Padilla, A. (1998). Student motivation, parental attitudes, and involvement in the learning of Asian languages in elementary and secondary schools. The Modern Language Journal. 82, 205-216.

Tao, A. \& Li, X. (2014). Relationship between critical thinking and personality based on the history of psychology teaching. American International Journal of Social Science. 3 (5), 88-93.

Wakamoto, N. (2000). Language learning strategy and personality variables: Focusing on extroversion and introversion. IRAL: International Review of Applied Linguistics in Language Teaching. 38 (1), 71-81.

Wakamoto, N. (2007). The impact of extroversion/introversion and associated learner strategies on English language comprehension in a Japanese EFL setting. Unpublished doctoral dissertation, University of Toronto, Canada.

Yashima, T. (1995). English proficiency, personality, and intercultural adjustment of Japanese students studying in America. Intercultural Communication Studies. 5 (1), 83-108. 